\title{
Alberto Toutin
}

Facultad de Teología

Pontificia Universidad Católica de Chile

\section{La luminosa sed. Esbozo de un itinerario de la manifestación del ser como deseo de ser al Dios deseante que viene a nuestro encuentro}

El realizador y director de cine belga, Luc Dardenne (1954), confiesa en una nota de su diario personal fechada el 10 de agosto de 1994, un cierto malestar cultural que toma la forma sintomática de una dificultad respiratoria, de un ahogo:

"Hay algo pesado, sofocante en la existencia. De donde esta necesidad irrefrenable de una apertura, de un afuera. Un ruego por aire que lanzan todas nuestras miradas, todas nuestras palabras, todos nuestros rostros, todos nuestros cuerpos oprimidos. Necesidad extrema de lo que no existe. Nuestra época tiene graves problemas de respiración" (1).

Esta nota revela a la vez un diagnóstico y una aspiración. El diagnóstico es el de estar viviendo en una época saturada de imágenes, de documentales que buscan presentar la realidad, en lo que ella tiene de más urgente y por lo mismo de más obvio. Pero esta presentación, en lugar de mostrar la realidad en lo que en ella está más allá de lo obvio, la enmascara en la medida en que no permite efectivamente un acceso a lo hay de más genuino, de más auténtico en ella. Se contenta con ser una mera representación de la realidad, saturada de ella misma, teñida por una estética victimaria de cuerpos sufrientes, destruidos y desfigurados pero sin que dichos cuerpos hablen de las causas de estos sufrimientos y, por lo tanto, del mal que hay que combatir y no sólo del mal del que hay que apiadarse. Y esta nota expresa una aspiración que tenazmente pervive en el corazón humano y es la necesidad de una apertura, de un afuera, no para que nos saque o evada de la realidad en sus aspectos desafiantes o enigmáticos sino que nos adentre en lo que en ella hay de invisible, de inefable, de aún no realizado y que late en ella como su pulsación interna. Y ello se transparenta en los rostros, palabras y cuerpos que están ahí, en el día a día, que claman de esta necesidad pero que o bien no hay la antena para sintonizar con este reclamo o no hay aún las imágenes

(1) Luc Dardenne, Au dos de nos images 1991-2005. Paris: Seuil, (“Librairie du XXIe siècle”), 2005, p. 43. 
o palabras que lo puedan sacar de su mutismo impalpable. Para hacerse cargo de este diagnóstico y satisfacer a la necesidad de ver más allá de lo obvio, se requiere de finos escrutadores de la realidad que sean capaces de percibir, en la opacidad del día a día, la respiración anhelante de esa apertura y de un afuera que nos permita acceder a nosotros mismos, a lo que somos y a lo mejor de nosotros mismos que quisiéramos ser. En este trabajo proponemos a Octavio Paz (1914-1998), poeta y ensayista mexicano y Hans Urs von Balthasar (1905-1988), teólogo suizo como dos finos escrutadores de la realidad: cada uno buscó hacerse cargo de este diagnóstico de asfixia cultural y de la consiguiente necesidad de abrir una brecha, para que otro aire entre y renueve las aspiraciones profundas de los seres humanos. Para ello, cada uno exploró instancias reveladoras distintas: Octavio Paz el lenguaje poético y su capacidad de decir el ser del hombre y Hans Urs von Balthasar la palabra de Dios, pronunciada definitivamente en Jesús en quien Dios habla como hombre y por quien éste es capaz de decirse en su ser propio y hablar de Dios y a Dios. Nos interesa mostrar en esta ponencia de qué manera la poesía o decir poético para el primero y la palabra de Dios para el segundo se ofrecen como espacios de revelación de lo que está dormitando dentro de la realidad y del ser humano, y de otra realidad que irrumpe en efímero aquí y ahora.

\section{LA POESÍA, UMBRAL HACIA OTRO MUNDO Y ECO DE OTRA VOZ}

Octavio Paz se pregunta con un frescor admirativo por este modo particular de recibir el mundo y de acceder a él que es la poesía. Este modo de expresión se caracteriza por una alquimia "de ritmo, repetición creadora, la imagen -haz de sentidos rebeldes a la explicación” (2). ¿Por qué existe la poesía? ¿Por qué necesita el ser humano este modo peculiar de expresión? ¿Qué explica que el poeta sienta una deuda contraída con la realidad que lo afecta en su ser y que lo impulsa a pagar esta deuda en el decir poético, esto es, en el tener algo que decir de esta forma? ¿Qué es lo que allí se dice de manera específica del ser humano, del mundo en el que habita?

Dejemos al poeta chileno Pablo Neruda (1904-1973) que diga con sus propias palabras lo que le aconteció cuando la poesía irrumpió en su vida:

"Y fue a esa edad...Llegó la poesía

a buscarme. No sé, no sé de dónde

salió, de invierno o río.

No sé cómo ni cuándo,

no, no eran voces, no eran

palabras, ni silencio,

pero desde una calle me llamaba,

desde las ramas de la noche,

de pronto entre los otros,

entre fuegos violentos

$\mathrm{O}$ regresando solo,

(2) Octavio Paz, El arco y la lira. Fondo de Cultura Económica: México, 1992, p. 117. 
Allí estaba sin rostro

y me tocaba" (3).

A las preguntas que Octavio Paz formula sobre el quehacer poético, Neruda responde que la poesía es algo o alguien que aparece intempestivamente en la vida del poeta. La poesía es personificada en un sujeto capaz de acción -viene a buscar, llama, permanece y toca. Su llegada se caracteriza por sumir al visitado en un nosaber: sobre su origen, sobre su modo y tiempo de llegar. Su realidad es paradójica pues es anterior a la palabra, a la voz y al silencio y, sin embargo, llama de manera perentoria. Su presencia se anuncia en el poeta, tan sólo escucha la sutil vibración de sus llamadas, sin rostro ni figura que la singularice o identifique. Y, sin embargo, sus llamadas son eficaces pues tocan en el interior al poeta- y lo alcanza secretamente en lo recóndito de su soledad. La visita inesperada de la poesía se deja presentir en el poeta primero por un desconcierto, por un no saber que lo toca y conmueve desde dentro, y luego por una respuesta a una llamada que resuena de todas partes y con fuerza en el interior del poeta.

A partir de los testimonios de los poetas sobre sus creaciones, Paz percibe dos enigmas que surgen del quehacer poético. El primer enigma tiene que ver con que el decir poético, su expresión aparece en el lenguaje tomando distancia de la realidad, tal como la vemos y sentimos. Es verdad que los objetos poetizados -elementos de la naturaleza, estaciones del año, lugares, personas, etc, son tomados de la realidad en la que vivimos y son designados mediante la lengua de todos los días. Pero esos objetos y el lenguaje que les designa en el poema han sido transmutados, transfigurados. El decir poético opera una suspensión de la dimensión comunicativa o informativa del lenguaje cotidiano, regida por las leyes del intercambio de noticias o datos. Esta suspensión conlleva una puesta en entredicho de la realidad poetizada. Volviendo al poema de Neruda, "la calle" no es la calle y "la noche" no es simplemente la noche. La calle es el lugar desde donde llama la poesía y la noche está dotada de ramas -como un árbol vivo entre cuyo ramaje la oscuridad se deja entrever. Las expresiones "calle" y "noche" son arrancadas de su significación habitual, coloquial y se abren no sólo a una nueva significación sino a un ser nuevo que brilla en el interior del poema. Octavio Paz describe este proceso de retorno sobre sí mismo del lenguaje en el poema al modo de un ser vivo que se enrolla sobre sí mismo:

"En el poema, la linealidad se tuerce, vuelve sobre sus pasos, serpea [...] Hay un momento en que el lenguaje deja de deslizarse; y, por decirlo así, se levanta y se mece sobre el vacío; hay otro en el que cesa de fluir y se transforma en un sólido transparente -cubo, esfera, obelisco- plantado en el centro de la página. Los significados se congelan o se dispersan; de una y otra manera, se niegan. Las palabras no dicen las mismas cosas que en la prosa; el poema no aspira ya a decir sino a ser" (4).

(3) Pablo Neruda, "La poesía", Memorial de Isla Negra (1964) en Antología Elemental. [Prólogo, selección y referencias bibliográficas de Jaime Quezada y Floridor Pérez], Santiago de Chile: Andrés Bello, 2003, p. 167.

(4) Octavio Paz, La llama doble. Amor y erotismo. Buenos Aires. Seix Barral, 1996, p. 11. 
Es por este movimiento del lenguaje que vuelve sobre sus pasos en el poema que se ha dicho que la poesía no busca, en primera instancia, otra cosa sino celebrarse a ella misma. Y sólo aceptando esta condición primera, el lector así como el poeta mismo pueden entrar en el festín de las palabras.

$\mathrm{Y}$ el segundo enigma que surge del quehacer poético tiene que ver con la voz del que habla en el poema, la voz poética. Por mucho que esa voz aparezca en el poema designada por el pronombre personal en primera persona singular "yo", ese yo, no coincide necesariamente con el yo del poeta. En primer lugar porque el pronombre personal yo, si bien asume su significación del lenguaje coloquial, en el poema ese mismo pronombre cobra una nueva significación, distanciada de su circulación en el habla habitual. Y en segundo lugar, porque dicha distancia dice de un proceso que vive el poeta mismo en donde lo que él escribe y dice responde obediencialmente a una voz que viene del poeta pero que es más fuerte que él, que se expresa en sus palabras pero que viene de un terreno primordial, anterior a las palabras y a los silencios. En el momento de la expresión poética propiamente tal hay "siempre" una colaboración fatal e inesperada, que puede darse con el concurso de la voluntad del poeta o sin ella. Es la irrupción de "otra voz" que le impele a "tener que decir algo" y que no sabe ni dónde proviene ni de qué se trata sino hasta que lo expresa. Paz, recogiendo también su propia experiencia como poeta, se pregunta: “Cómo se llama, quién es ese que [irrumpe e] interrumpe mi discurso y me hace decir cosas que yo no pretendía decir?" (5).

Estos dos enigmas convergen entonces sobre una doble paradoja: ¿Qué dice la poesía si su lenguaje se vuelve sobre sus pasos y se celebra a sí mismo? ¿Quién habla en el poema si su mismo creador obedece a una voz que, a menudo, se le impone y le hace decir lo que él no sabía que iba a decir?

Tanto la puesta en entredicho de la realidad poetizada como la irrupción de esa otra voz que habla en el poeta están el servicio de hacer ver ese otro mundo que yace en el transcurrir del mundo que vemos y que aparece. Esa "otredad" del mundo expresa en el poema no sólo en lo que el mundo es y aparece sino en lo que puede ser y permanece latente. Lo que se muestra incluso, lo que se revela en el poema no es el ser en su facticidad sino más bien en sus posibilidades de ser. El ser que se muestra en sus posibilidades afecta no sólo a la realidad poetizada sino al poeta mismo, en su comprensión de sí y en su relación al mundo.

Y para ver ese otro mundo en sus posibles ni poeta ni nosotros podemos vadear esa crecida de realidad que es el poema. En efecto, el poema traza un modo de acceso a esa otredad que surge precisamente de las cenizas de la significación habitual de las cosas en el habla cotidiana y de la respuesta del poeta a las llamadas de esa otra voz que provienen enigmáticamente de las cosas y que resuenan en su interior, interpelándolo al proferir poético.

Dichas posibilidades de ser sólo son accesibles y reconocibles en la medida en que el poeta les hace venir al lenguaje del poema. Sin este esta mayéutica del decir poético, estas posibilidades permanecerían confinadas en el reino de la in-significancia. Hay un ver el ser, desde el ángulo de sus posibilidades inéditas e inexploradas,

(5) Octavio Paz, El arco y la lira. Fondo de Cultura Económica: México, 1992, p. 157. 
gracias al escuchar la otra voz que habita al poeta y al traducirla en la palabra en el verso. De esta revelación del mundo y del poeta mismo en sus posibilidades inéditas de ser nos habla Neruda cuando el poeta decide salir de su mutismo y obedecer a la voz que lo impele a nombrar poéticamente las cosas y a ponerlas por escrito:

"Yo no sabía qué decir, mi boca

no sabía

nombrar,

mis ojos eran ciegos,

y algo golpeaba mi alma,

fiebre o alas perdidas,

y me fui haciendo solo,

descifrando

aquella quemadura,

y escribí la primera línea vaga,

vaga, sin cuerpo, pura

tontería,

pura sabiduría

del que no sabe nada,

$\mathrm{y}$ vi de pronto

el cielo

desgranado

y abierto,

planetas,

plantaciones palpitantes.

la sombra perforada,

acribillada

por flechas, fuego y flores

la noche arrolladora, el universo" (6).

El poeta sale de su ignorancia e incertidumbre, obedeciendo a esa otra voz, a "ese algo que golpeaba su alma". Es el trabajo de escritura que hace posible que el poeta vea. Este ver no es simplemente del orden físico u óptico sino del orden de un desciframiento de sí mismo y de lo que le rodea. Él ve "la sombra perforada, acribillada, por flechas, fuego y flores, la noche arrolladora, el universo". El verbo poético es lo que dispone al ser entero poeta y al lector -en su sensibilidad, inteligencia, imaginación y voluntad- a una visión nueva de sí mismo y de la realidad. De esta manera, el verbo poético hace ver y advenir la realidad poetizada en sus posibilidades, hasta entonces, insospechadas de ser. El nombrar del poeta tiene entonces la capacidad no sólo de mostrar al poeta mismo y su mundo sino incluso de redimirlos, desalojándolos de su finitud e insignificancia y desplegándolos en su respuesta a lo que están llamados a ser. Esta es la dimensión creativa que tiene la revelación poética.

(6) Pablo Neruda, "La poesía”, Memorial de Isla Negra (1964) en Antología Elemental. [Prólogo, selección y referencias bibliográficas de Jaime Quezada y Floridor Pérez], Santiago de Chile: Andrés Bello, 2003, pp. 167-168. 
Para decir el ser de esta manera, el lenguaje necesita poner en entredicho la realidad y suspender o al menos desviar la función comunicativa o directamente referencial del lenguaje. Es lo que sintetiza Octavio Paz cuando escribe:

"Poetizar, consiste en primer término en nombrar. La palabra distingue la actividad poética de cualquier otra. Poetizar es crear con palabras: hacer poemas. Lo poético no es algo dado, que esté en el hombre desde su nacimiento, sino algo que el hombre hace y que, recíprocamente, hace al hombre. Lo poético es una posibilidad, no una categoría a priori ni una facultad innata. Pero es una posibilidad que nosotros mismos nos creamos. Al nombrar, al crear con palabras, creamos eso mismo que nombramos y que antes no existía sino como amenaza, vacío y caos. Cuando el poeta afirma que ignora "qué es lo que va a escribir" quiere decir que aún no sabe cómo se llama eso que su poema va a nombrar y que, hasta que sea nombrado, sólo se presenta bajo la forma de silencio ininteligible. Lector y poeta se crean al crear el poema que sólo existe por ellos y para que ellos de veras existan.[...] Lo propio de la poesía consiste en ser una continua creación y de este modo arrojarnos de nosotros mismos, desalojarnos y llevarnos hacia nuestras posibilidades más extremas" (7).

Si la puesta en entredicho de lo real en la poesía y la suspensión de la función comunicativa del lenguaje permiten la revelación, la otredad del ser, su posibilidad de ser de otra manera, la otra voz que habla en el poeta, la "inspiración" que irrumpe en él, lo pone ante la otredad que habita en él mismo y que es inherente a su ser en el mundo:

"La inspiración es una manifestación de la "otredad" constitutiva del hombre. No está adentro, en nuestro interior, ni atrás, como algo que de pronto surgiera del limo del pasado que está, por decirlo así, adelante: es algo (o mejor: alguien) que nos llama a ser nosotros mismos. Y ese alguien es nuestro ser mismo. Y en verdad la inspiración no está en ninguna parte, simplemente no está, ni es algo: es una aspiración, un ir, un movimiento hacia delante: hacia eso que somos nosotros mismos" (8).

Ese algo o alguien o, en lenguaje de Neruda, ese "algo que golpeaba el alma", esa "otra voz" que conspira con el poeta en su quehacer creativo, habla de un ser que se descubre en el mundo, que extrañado y desconcertado ante lo que significa el existir, aspira a dar un sentido al "duro deseo de durar" (Paul Éluard), de cara a la muerte que ineluctable y sigilosamente viene al (des-) encuentro de este deseo. La otra voz del poeta expresa entonces que el ser de la realidad no es sólo posibilidad de ser sino también y más radicalmente deseo de ser, amenazado por la imposibilidad de ser, la nada y la muerte. O más precisamente, la posibilidad de ser de la realidad que late en la realidad adviene a lo que está llamada a ser gracias al deseo de ser que se expresa y se realiza en la otra voz que habla en el poeta. El llamado que la poesía

(7) Octavio Paz, El arco y la lira. Fondo de Cultura Económica: México, 1992, p. 167.

(8) Octavio Paz, El arco y la lira. Fondo de Cultura Económica: México, 1992, p. 179. 
dirige al poeta desde las calles y entre los otros se ve amplificado por la sed de ser otro y hacia el otro; sed cuyo portavoz y escanciador es el poeta. Al respecto, escribe Paz: "El ser del hombre contiene ya a ese otro ser que quiere ser. "La amada -dice Machado- es una con el amante, no al término del proceso erótico sino en su principio". La amada está ya en nuestro ser como, como sed y "otredad". Ser es erotismo. La inspiración es esa voz extraña, que saca al hombre de sí mismo para ser todo lo que es, todo lo que desea: otro cuerpo, otro ser. La voz del deseo es la voz misma del ser, porque el ser no es sino deseo de ser" (9).

De este modo, la otredad del mundo que se transparenta en el poema y con la otra voz que lo anuncia en él, Paz pone las bases de la comprensión de la poesía como una "erótica verbal" (10). En efecto, así como la imaginación permite desviar o poner en entredicho la orientación reproductiva de la sexualidad y transfigurarla en rito, juego amoroso, placer y ceremonia en el erotismo, así también la imaginación pone en entredicho la función comunicativa del lenguaje para orientarla hacia la otredad del mundo y hacia el deseo de ser (con) otro. Ahora bien, ello es posible con el concurso de la imaginación que opera una metaforización de la sexualidad y del lenguaje, un llevarlos más allá de ellos mismos ¿Qué significa? Desde el interior del erotismo como "poética sensible" hay una orientación hacia un tú, que ensancha el deseo de encuentro y lo advierte del riesgo autodestructor de toda forma narcisista de realizar sus posibilidades de ser. Del mismo modo desde el interior del poema -como "erótica verbal"-, desde la precariedad del deseo de ser que lo trasunta hay una orientación hacia un más allá del poema, hacia un ser otro y que puede cobrar la figura de un tú concreto o de una sed o anhelo insaciable de encuentro. Octavio Paz expresa así en el lenguaje de la poesía como "erótica verbal", la aventura arriesgada y sinuosa del amor y que tiene como protagonista al deseo de ser que se encamina al tú del amado o amada:

"Como todo movimiento del hombre, el amor es un "ir al encuentro". En la espera todo nuestro ser se inclina hacia delante. Es un anhelar, un tenderse hacia algo que aún no está presente y que es una posibilidad que puede no producirse: la aparición de la mujer. La espera nos tiene en vilo, es decir, suspendidos, fuera de nosotros. Hace un minuto que estábamos instalados en nuestro mundo y nos movíamos con tal naturalidad y facilidad entre las cosas y seres que no advertíamos su distancia. Ahora, a medida que crecen la impaciencia y el anhelar, el paisaje se aleja, el muro y las cosas de enfrente se retiran y repliegan sobre sí mismas y el reloj marcha más despacio. Todo se ha puesto a vivir una vida aparte, impenetrable. El mundo se hace ajeno. Ya estamos solos. La espera misma se vuelve desesperación, porque la esperanza de la presencia se ha trocado en certidumbre de soledad. No vendrá. No habrá nadie. No hay nadie. Yo mismo no soy nadie. La nada se abre a nuestros pies. Y en ese instante sobreviene lo inesperado, lo que ya no esperábamos. El goce ante la irrupción de la presencia amada se expresa como una suspensión del ánimo; nos falta suelo, nos faltan palabras, la alegría nos corta la respiración. Todo se queda inmóvil, a

(9) Octavio Paz, El arco y la lira. Fondo de Cultura Económica: México, 1992, p. 180.

(10) Octavio Paz, La llama doble. Amor y erotismo. Buenos Aires. Seix Barral, 1996, p. 10. 
mitad del salto en el vacío. El mundo impenetrable, ininteligible e innombrable, cayendo pesadamente sobre sí mismo, de pronto se levanta, se yergue, vuela al encuentro de la presencia. Está imantado por unos ojos, suspendido a un misterioso equilibrio. Todo había perdido sentido y nosotros estábamos al borde del precipicio de la existencia bruta. Ahora todo se ilumina y cobra significación. La presencia rescata al ser. O mejor dicho, lo arranca del caos en que se hundía, lo recrea. Nace el ser de la nada. Pero basta con que no me mires para que todo caiga de nuevo y yo mismo me hunda en el caos. Tensión, marcha sobre el abismo, marcha sobre el filo de una espada. Tú estás aquí, cifra del mundo, cifra de mí mismo, cifra del ser" (11).

La aventura amorosa, el encuentro arriesgado del tú es para Octavio Paz una experiencia ontofánica, es decir reveladora del ser, de sus anhelos, riesgos y posibilidades. Es el deseo del ser humano que se encamina hacia el ser (con) otro, desde su sed y anhelo profundo de encuentro. Es esta misma lógica pero en un sentido inverso la que adopta Dios en su revelación. El deseado de todos los tiempo, Dios que viene al encuentro del ser humano deseante, de su pueblo peregrinante, de la creación gimiente. Es Dios que desea acercarse al ser humano. Y para hacerlo no lo hace de una manera difusa o vaga sino que habla y lo hace claramente a través de su palabra. Dios es el poeta de su propia automanifestación. Veamos las características que adopta la poética de Dios en su hablar, guiados por algunos escritos de Hans Urs von Balthasar.

\section{CUANDO EL DESEO DE DIOS SE VUELVE PALABRA}

Balthasar asume como punto de partida de su reflexión acerca de la autorrevelación de Dios el que lo haya hecho a través de la palabra. Más allá de todas las purificaciones de antropomorfismos que haya que introducir en el lenguaje que habla de Dios, Balthasar invita a mirar con ojos nuevos el hecho que Dios, para revelarse, habla y lo hace de manera que el ser humano lo puede entender. Una de las expresiones más osadas al respecto, es la que encontramos en la relación que Dios establece con Moisés. El Dios celoso y libertador de Israel, al que nadie puede acercarse y permanecer vivo, este Dios trascendente y poderoso es el que decide hablar con su mediador y caudillo, con Moisés, "cara a cara, como habla un hombre con un amigo". (Éxodo 34,7) Cuando Dios habla expresa no sólo su querer, sus mandatos sino que se comunica Él mismo, manifestando su pathos o amor tenaz para con su Pueblo y actuando eficazmente en su favor. Y ello Dios lo hace en un lenguaje que resulta comprensible a sus destinatarios, ya sea dirigiéndoles Él directamente la palabra o haciéndolo a través de sus mediadores. Las Escrituras recogen así el hablar actuante de Dios o su actuar hablante y narran de diversas maneras el deseo pertinaz de Dios de venir al encuentro del ser humano, de su pueblo. $Y$ en el mismo movimiento por el que Dios se dice, expresa también su querer y su anhelo para el ser humano y lo

(11) Octavio Paz, El arco y la lira. Fondo de Cultura Económica: México, 1992, pp. 152-153. 
revela en su ser más hondo, ofreciéndole así un espacio para que éste pueda realizarse en su condición de creatura responsorial al decir creador de Dios: "Ser hombre significa ser interpelado por Dios en la Palabra y ser creado a imagen y semejanza de Dios de tal manera que uno pueda oír la Palabra y darle respuesta" (12).

El hablar de Dios, tal como es recogido en las Escrituras, muestra también a un Dios que restablece permanentemente la relación con el ser humano. Las brechas que el hombre haya podido introducir en esta relación, Dios las colma y las supera. Él rompe el silencio que puede instalarse en la relación entre Él y el ser humano. Incluso el mutismo de Dios o su palabra enjuiciadora apunta a menudo a derribar los obstáculos y barreras que se interponen entre Él y la capacidad de escucha y de respuesta del ser humano. De esta manera Dios al comunicarse con la lengua de los hombres, ofrece a éstos las palabras con las que ellos mismos puedan invocar a Dios, reconocerlo en el tiempo y dirigirse a Él.

Esta lógica que Dios despliega como poeta en su hablar al ser humano se encuentra asumida y radicalizada en la Encarnación de su Verbo, su Hijo eterno en Jesús. En Jesús, en su peregrinar en la tierra, en sus decisiones y opciones, en su sentir y actuar, Dios no sólo cobra un rostro y una palabra humanas sino que también el rostro y la palabra humanas son capaces de decir y expresar el ser y desear de Dios. La Encarnación del Verbo de Dios se hace en beneficio de una humanidad concreta, la de Jesús de Nazaret. Éste se manifestó primero como el poeta de su propia predicación el exégeta de Dios su Padre. Su persona, sus acciones y su palabra, en sus distintos registros, se constituyeron en el rostro y el lenguaje humanos de Dios, de su querer, de su acción. Incluso más, para decir la hondura del amor de Dios por el ser humano más allá de lo esperable, Jesús, la Palabra de Dios, hecha lenguaje humano, se expuso a ser enmudecida. En efecto, ella adoptó la forma más elocuente que puede haber en la experiencia humana para decir el amor que no tiene medida y que desarma toda lógica narcisista o calculadora que es la de de un cuerpo gimiente, entregando la propia vida por el bien de otro:

"Lo que no es capaz de hacer la palabra hablada -que sólo incita a una creciente resistencia-, lo consigue la palabra sacrificada (das hingeopfert Wort), que se derrama gota a gota en las palabras de la cruz y que, finalmente, se extingue del todo en el tremendo, en el inarticulado grito de la muerte, que resume todo: lo dicho, lo no dicho y lo indecible que Dios tenía que comunicarnos” (13).

De esta manera, Jesús exégeta del amor de Dios, asume hasta el límite de las posibilidades de expresión el lenguaje y de la existencia humana para decir lo más inefable y desbordante del ser de Dios, su amor de Padre que, en Jesús crucificado y resucitado, se hace solidario de la enigmática finitud y mortalidad del ser humano y de la creación entera. La Palabra sacrificada y anonadada de Jesús es la que mejor dice lo inefable e insondable del ser de Dios. La paradoja que atraviesa el hablar de

(12) Hans Urs von Balthasar, "Wort, Schrift, Tradition" in Verbum Caro. Skizzen zur Theologie. Einsiedeln: Johannes Verlag, 1960, pp. 23-24.

(13) Hans Urs von Balthasar, "Gott spricht als Mensch" in Verbum Caro. Skizzen zur Theologie. Einsiedeln: Johannes Verlag, 1960, p. 89. 
Dios en la lengua del hombre y que se consuma en la cruz de Cristo, Balthasar la expresa de la manera siguiente: "Cuanto más profundamente se descubre Dios, tanto más hondamente se oculta dentro del hombre" (14).

Esta paradoja que existe en el modo como Dios se dice de manera inaudita en Jesús es la que se conserva también en las Escrituras que recogen el acontecimiento de Jesús para nosotros. Estas palabras nos narran a Jesús, su decir y su actuar, las opciones que lo condujeron a la muerte en la cruz y cómo Dios rehabilitó a su hablar silenciado, resucitando a Jesús y tendiendo un puente definitivo entre la vida que Dios desea compartir y el ser humano. Pues bien, éstas palabras nos hablan de la nueva presencia de Jesús ahora Resucitado, rostro anticipado del deseo definitivo de Dios por la humanidad. Y continuando Jesús como poeta y exégeta de su nueva condición, él mismo explica las Escrituras, su autoridad y calidad de presencia se la reconoce ahora por un ardor nuevo que deja en el corazón de sus discípulos y por los ojos transfigurados que lo ven en una ausencia actuante que les hace ponerse en camino al encuentro de la comunidad de sus testigos (Cf. Lucas 24, 13-35). La poética teológica de las Escrituras narra entonces el entredicho definitivo que Jesús puso en su propia carne a la muerte y a su poder destructor y remite al Ausente que sigue actuando y que se manifiesta ocultándose en el presente de su cuerpo peregrinante en la historia, en la humanidad de la que Dios ha hecho su alfabeto.

\section{EL SER HUMANO, ALFABETO DE DIOS. ALGUNAS PERSPECTIVAS TEOLÓGICAS}

Explicitemos dos consecuencias concernientes a la relación entre palabras humanas y la Palabra de Dios y lo humano como revelador de Dios a la luz de poética teológica de las Escrituras que recogen la historia del Dios que habla como hombre y del acontecimiento de Jesús, la palabra definitiva de Dios sobre sí mismo y sobre el ser humano.

a) Lo que el hombre es y dice, es capaz de expresar, en lenguaje creatural, a Dios, su deseo y su acción hoy. Esto implica reconocer que el ser humano, en sus posibilidades y deseo de ser es portador de un anhelo de vida, que va más allá de la fisura ontológica de la muerte, y de encuentro con el o los otros, que es más tenaz que las frustraciones y los desencuentros. De estas posibilidades de ser y del deseo de ser habla, entre otros lenguajes, el verbo poético. Si este verbo traza el camino del deseo del ser humano hacia su bienestar y su ser más con los otros, el Verbo de Dios expresado en la humanidad de Jesús y recogido en las Escrituras, hablan del deseo de Dios de encontrarse con toda la humanidad y de encaminarla hacia las posibilidades de ser que ya ha manifestado irrevocablemente en la carne resucitada de Jesús. "Sin duda, lo que el hombre es y lo que el hombre puede ser sólo se revela en su plenitud allí donde Dios lo ha convertido en alfabeto suyo, en cuerpo suyo, de sonido y

(14) Hans Urs von Balthasar, "Gott spricht als Mensch" in Verbum Caro. Skizzen zur Theologie. Einsiedeln: Johannes Verlag, 1960, p. 91. 
sentido. (Freilich, was der Mensch ist und sein kann, das offenbart sich in seiner Fülle erst Dort, wo Gott ihn zu seinem Alphabet, seinem Klang-und Sinnkörper macht)" (15). Desde este alfabeto creatural pronunciado en Jesús, el creyente puede descifrarse en su propia condición enigmática y cifrar su esperanza, junto con los deseos de ser que mueven a la humanidad. Pero, al mismo tiempo, si el decir y el ser del hombre se vuelven exposición y explicación de Dios, de su deseo y acción, ello se dice en el lenguaje creatural, por lo tanto jamás es Dios mismo. De esta distancia paradójica nos hablan las Escrituras que recogen el acontecimiento de Jesús, a saber, la mayor manifestación de Dios en el mayor ocultamiento en el ser del hombre. Pues bien, esa misma distancia es la que permanece en la capacidad de lo humano de revelar a Dios. Dios es Dios y su distancia con respecto a la creatura ha de manifestarse como tal en el ser del hombre y en el lenguaje que tienda a expresarlo. Así, el lenguaje poético por ejemplo, será más capaz de decir la presencia o ausencia de Dios cuanto más liminar o abierto a la realidad abismal del ser del hombre permanezca y cuanto más decididamente lo conduzca a ella. Así el poema de Neruda que hemos visto anteriormente desemboca en una nueva conciencia del poeta, de su pequeñez frente a su propia precariedad ontológica -sin fundamento y amenazado por la finitud- $\mathrm{y}$ ante la inmensidad del universo:

"Y yo mínimo ser, ebrio del gran vacío constelado, a semejanza, a imagen del misterio, me sentí parte pura del abismo, rodé con las estrellas mi corazón se desató con el viento" (16).

Hay una aspiración de trascendencia que surge desde esta abismante finitud y que se expresa en una honda comunión de su ser y de su corazón con lo que hay de más lejano -el firmamento- y más sutil -el viento- en el universo de lo creado.

A la luz de la humanidad de Jesús, el decir y ser del hombre será más capaz de decir a Dios, cuanto más se hagan atentos a su acción y su deseo de ser con y para el ser humano, cuyos destellos brillan desde lo abismal de la existencia.

b) La condición peregrinante y transitoria de la verdad sobre el ser de Dios y del ser del hombre. La poesía como erótica verbal posee una dimensión ontofánica. En ella el ser es arrancado de sí mismo por el encuentro del ser humano

(15) Hans Urs von Balthasar, "Gott spricht als Mensch" in Verbum Caro. Skizzen zur Theologie. Einsiedeln: Johannes Verlag, 1960, pp. 90-91.

(16) Pablo Neruda, "La poesía”, Memorial de Isla Negra (1964) en Antología Elemental. [Prólogo, selección y referencias bibliográficas de Jaime Quezada y Floridor Pérez], Santiago de Chile: Andrés Bello, 2003, p. 169. 
consigo mismo, con las cosas, con los acontecimientos, con los otros, y el poeta es convocado a responder mediante la palabra de cada uno de estos encuentros, llevándolos a la plenitud de sus posibilidades de ser en el poema. De este modo, el poeta se hace portavoz del conjunto de lo creado, en sus anhelos de plenitud ya que en él mismo irrumpe ese anhelo como esa "otra voz", la voz del deseo de ser que conspira con él en todos sus decires. La posibilidad de ser otro, de otras formas posibles de habitar el mundo y de relacionarse con él, y la sed de ser otro, que es sed de bien-estar y de ser-más con los otros, ponen arriesgadamente a la poesía en marcha al encuentro de un tú; un tú que ya está de manera incoada en el poeta como secreto deseo y que permanece en él como la ardiente paciencia que lo sostiene en una tarea inacabada y siempre por recomenzar, la de ir al encuentro del tú. Esta travesía del deseo de ser hacia el tú, la poesía lo hace en condición de mendigo y de peregrino. Como mendigo pues el ser otro al que aspira su deseo de ser, no lo alcanza por él mismo sino que requiere de la conspiración del deseo del otro que venga a su encuentro. Es el otro el que, más allá de lo esperado, puede aportar ese "plus" de ser al que aspira. Y como peregrino, pues la poesía se lanza en esta aventura en las rutas del tiempo, haciéndose cargo de su propia finitud y corriendo el riesgo de los desencuentros, de los intentos fallidos y de los rechazos. No hay posibilidad de que el deseo de ser pueda realizarse sin esta actitud de disponibilidad a que el otro venga como otro, en sus tiempos y plazos propios, y de humildad para dejar que el otro venga por los caminos que el deseo nunca imaginó.

Las Escrituras nos narran la historia del Dios deseante que también se pone en camino hacia el hombre. Ellas lo hacen también en condición mendicante, no por indigencia sino porque, de alguna manera, como lo muestra la parábola del hijo pródigo, el ser Padre de Dios no se realiza del todo sino hasta que cada uno de sus hijos vuelva a él y acepte su invitación a la fiesta del amor reconciliante. Este venir de Dios es arriesgado pues asume desde dentro la condición de finitud del ser humano y también se expone a su libertad, en lo que ella tiene de más noble y perverso. De esta manera, el ser mismo de Dios -que es darse amorosamente- y su querer irrevocable para con el ser humano -la plenitud de su condición filial-, se realizan ya en el transcurrir del tiempo y aún más allá. Las Escrituras describen el peregrinar de Dios que no se cansa ni desespera en su deseo de venir a nuestro encuentro y abre caminos inéditos a nuestro propio peregrinar para encontrarnos con él.

"Toda la escritura permanece en camino (Die gesamte Schrift bleibt unterwegs) -escribe von Balthasar-; está siempre a punto de partir, avanza por el desierto, desde la imagen hacia la verdad, desde la promesa hacia el cumplimiento, desde la palabra hacia la carne, pero también desde la muerte de la carne hacia la vida del espíritu. La Escritura avanza desde el presente de carne (a través de la ausencia producida por la muerte y la ascensión al cielo) hacia el presente escatológico: esta verdad plena está hecha de distensión ("diástasis"); es verdad del "cor inquietum", verdad de la esperanza y del amor lleno de nostalgia. Y dentro de esa experiencia humana se introduce la verdad divina; esa delicada red de relaciones temporales es suficientemente fuerte para captar 
la verdad absoluta, al cual, en efecto, es una verdad de relaciones eternas en una vida eterna" (17).

En este camino arriesgado al tú en donde Dios encuentra su placer. Su deseo de ser encuentra su plenitud en el ser humano -varón y mujer- que lo busca y lo acoge en los caminos que traza la tarea de existir. Es por ello que el amor auténticamente vivido es una epifanía del Dios cuyo deseo se complace en el marchar junto al ser humano, asomarse por los entresijos de sus búsquedas y encaminarlo peregrina y mendicantemente a su plenitud. ¿No están aquí puestas las base de una erótica teológica todavía por hacer? En espera de ello, escuchemos las palabras con las que Esteban Gumucio, sacerdote y poeta chileno (1914-2001), atisba al Dios deseante que peregrina en los pasos de los amantes y de cuyas bocas surge esta invitación:

"El Dios transformante nos tomó de la mano, nos introdujo al país abierto,

a la región de la libertad.

Invitémonos a caminarlo, porque a Dios para conocerlo hay que caminarlo, al paso del día y de la noche.

Que calle tu corazón en el mío, que seamos silencio.

Él será susurro, paz, dolor aceptado, rocío, mirada, beso... (18)”.

\section{RESUMEN}

En este artículo se presenta un primer atisbo de un itinerario de pensamiento que busca articular, por un lado, una comprensión de la poesía en Octavio Paz como manifestación del ser humano como apertura al otro, como deseo de ser y, por otro, la comprensión en Hans Urs von Balthasar del acontecimiento de la automanifestación de Dios, como expresión de su deseo de encuentro con el ser humano y que para ello adopta arriesgada y creativamente su lenguaje en la diversidad de sus expresiones. Con ello tan sólo queremos poner algunas bases para una poética teológica, ya iniciada tanto por Dios como por el hablar del ser humano, y que llama de ella misma a ser continuada y profundizada.

Palabras clave: Poesía, Octavio Paz, Otredad, Ontofanía, Palabra de Dios, Von Balthasar, Automanifestación de Dios, literatura y teología.

\section{ABSTRACT}

In this article, the author presents a first glimpse of an itinerary of thought that seeks to articulate, on the one hand, an understanding of poetry by Octavio Paz as a

(17) Hans Urs von Balthasar, "Gott spricht als Mensch" in Verbum Caro. Skizzen zur Theologie. Einsiedeln: Johannes Verlag, 1960, p. 85.

(18) Esteban Gumucio, "Sacramento del amor humano" en Canto desde el centro de nuestra libertad. Santiago: Rehue, 1989, pp. 117-118. 
manifestation of the human being as openness to the other and as desire for being and, on the other hand, Hans Urs von Balthasar's understanding of the event of God's self-manifestation as the expression of His desire to meet the human being and, to that end, adopting, with risk and creativity, the human being's language in all the diversity of its expressions. With that, the author only wants to lay some foundations for a theological poetics, already initiated as much by God as by the speech of the human being, and which calls from its own self to be continuous and deepened.

Key words: Poetry, Octavio Paz, Otherness, Ontophany, Word of God, Von Balthasar, Self-manifestation of God, Literature and theology. 